\title{
Management of Wounds of Peripheral Arterial Disease Using Platelet Rich Plasma
}

Kshitija Ajay Chandanwale ${ }^{1}$ Chandrashekhar C. Mahakalkar², Abhishek Keruappa Kothule ${ }^{3}$, Dhiraj Vashdev Khithani ${ }^{4}$

${ }^{1}$ Department of General Surgery, Acharya Vinoba Bhave Rural Hospital, Sawangi (Meghe) Wardha, Maharashtra, India. 2Department of General Surgery, Jawaharlal Nehru Medical College, Sawangi (Meghe) Wardha, Maharashtra, India. ${ }^{3}$ Department of Obstetrics and Gynaecology, Acharya Vinoba Bhave Rural Hospital, Sawangi (Meghe) Wardha, Maharashtra, India. ${ }^{4}$ Department of General Surgery, Acharya Vinoba Bhave Rural Hospital, Sawangi (Meghe) Wardha, Maharashtra, India.

\section{ABSTRACT}

\section{BACKGROUND}

Arterial ulcers are caused by inadequate perfusion of skin and subcutaneous tissues. The key treatment is correcting the underlying medical problem and re-perfusion of the affected tissue. Interventional procedures like angiography, transluminal angioplasty, and stenting have hazards like bleeding, hematoma formation, false aneurysm formation etc. This study was conducted to investigate the effect of platelet-rich plasma (PRP) on the rate of healing of peripheral arterial wounds.

\section{METHODS}

A randomized controlled trial was conducted with 80 participants admitted with peripheral arterial disease in Acharya Vinoba Bhave Rural Hospital, Wardha district, Maharashtra, from September 2017 - August 2019. Data was entered into MS Excel and was analysed for descriptive statistics. 40 patients each were allotted randomly to control group and treatment group. In the control group, conventional dressings was done with hydrogen peroxide and betadine. Wounds were treated with PRP infiltration in the treatment group. Outcome was compared between both groups.

\section{RESULTS}

Mean surface area of wound in control group reduced from baseline $2262.5 \mathrm{~mm}^{2}$ to $1758.4 \mathrm{~mm}^{2}$ (29.89\% reduction) in ulcer surface area, and $2298.9 \mathrm{~mm}^{2}$ to 1158.1 $\mathrm{mm}^{2}(66.22 \%$ reduction) in treatment group ( $\mathrm{p}=0$ at the end of study) at the end of two months. Standard deviation of the same (Control: $1739.2 \mathrm{~mm}^{2}$ to $1566.3 \mathrm{~mm}^{2} \mathrm{vs}$ Treatment: $1906.5 \mathrm{~mm}^{2}$ to $1402.4 \mathrm{~mm}^{2}$ ). Rate of epithelization was faster in treatment group ( $8.92 \mathrm{~mm}^{2} /$ day vs $17.27 \mathrm{~mm}^{2} /$ day, $\mathrm{p}=0$ at the end of study). PRP resulted in early healing of ulcers with earlier reduction in wound surface area.

\section{CONCLUSIONS}

PRP is an effective method for healing of wounds resulting from peripheral arterial disease.

\section{KEY WORDS}

Platelet Rich Plasma, Wound Healing, Peripheral Arterial Disease, Rate of Epithelization
Corresponding Author: Dr. Kshitija Ajay Chandanwale, Department of General Surgery, Acharya Vinoba Bhave Rural Hospital, Sawangi (Meghe), Wardha, Maharashtra, India.

E-mail: dr.kshitijachandanwale@gmail.com

DOI: $10.14260 /$ jemds/2020/486

How to Cite This Article:

Chandanwale KA, Mahakalkar CC, Kothule $A K$, et al. Management of wounds of peripheral arterial disease using platelet rich plasma. J. Evolution Med. Dent. Sci. 2020;9(31):2239-2245, $10.14260 / \mathrm{jemds} / 2020 / 486$

Submission 14-04-2020,

Peer Review 22-06-2020,

Acceptance 29-06-2020,

Published 03-08-2020.

Copyright (C) 2020 JEMDS. This is an open access article distributed under Creative Commons Attribution License [Attribution 4.0 International (CC BY 4.0)] 


\section{BACKGROUND}

An ulcer is a break in continuity of the covering epithelium skin or mucous membrane occurring due to molecular death of the surface epithelium or its traumatic removal. ${ }^{1}$ Wounds are part of numerous, non-communicable diseases. They can occur due to ischemia, neuropathy, trauma, etc. Ischemic ulcers are caused by venous stasis, arterial occlusion, pressure, trauma, vasculitis, diabetes, etc.

Arterial ulcers are caused by inadequate perfusion of skin and subcutaneous tissues. They have a dramatically worsening effect, progressing to the 'critical limb ischemia' stage in the absence of treatment. According to the clinical picture and subjective patient aggravation peripheral arterial disease is divided in 4 stages according to Fontaine and 6 stages according to Rutherford. ${ }^{2}$ Stage IIb of Fontaine classification corresponds to Stage 2 of Rutherford stage. Multi-pronged strategy to salvage the affected limb includes off-loading, debridement with wound dressing and wound care. The key treatment is correcting the underlying medical problem and re-perfusion of the affected tissue. Treatments to revascularize comprise of various invasive endovascular and surgical methods. Interventional procedures like angiography, transluminal angioplasty and stenting though beneficial in locating and relieving occlusion/stenosis have hazards like bleeding, hematoma formation, false aneurysm formation, renal dysfunction, allergic reaction to contrast, distal embolization, arterial dissection, etc. ${ }^{3}$ and if done in the presence of pre-gangrenous changes may cause reperfusion injury, persistence of ischemia due to distal embolization and land into loss of organ.

Platelet-rich plasma (PRP) is a product that concentrates a large number of platelets in a small volume of plasma. PRP acts as a fibrin tissue adhesive with haemostatic and tissue sealing properties. It serves as a growth factor carrier. PRP accelerates endothelial, epithelial and epidermal regeneration, stimulates angiogenesis, enhances collagen synthesis, promotes soft tissue healing, decreases dermal scarring, enhances the haemostatic response to injury and reverses the inhibition of wound healing caused by glucocorticoids. The high leukocyte concentration of PRP has an added antimicrobial effect. As PRP is an autologous blood product, it carries no risk of transmitting infectious disease. ${ }^{4-6}$. It is been used for improving healing in various clinical fields including otolaryngology, orthopaedics, cardiovascular surgery, head and neck surgeries, healing in burns, periodontics and maxillofacial surgeries. It serves as a growth factor carrier. In clinical settings, it functions as a haemostatic agent minimizing incidents of intra and post-operative haemorrhage. It is also used in grafted tissues to promote growth by using its adhesive properties. It facilitates rapid vascularization. When PRP is used in combination with bone replacement materials, it induces the regeneration and accelerates healing. By generating signalling proteins that attract macrophages, platelets in PRP play a role in host defence mechanism at the wound site. ${ }^{7}$ Exploring other areas of wound management besides surgery is essential and benefits the rural and uneducated population immensely, both in terms of cost effectiveness, accessibility and compliance, which is what we aim for through this study by investigating the role of PRP in the management of arterial ischemic ulcers by the method of infiltration.

\section{METHODS}

This is a single center randomized controlled trial, performed on patients with arterial ulcer treated at Department of Surgery, J.N.M.C. and Acharya Vinoba Bhave Rural Hospital, Sawangi (Meghe), Wardha of DMIMS (DU), from September 2017-August 2019. Informed written consent was obtained from all the patients and prior approval from institutional ethical committee, DMIMS (DU) was taken.

\section{Inclusion Criteria}

Patients with peripheral arterial disease with ulcers over the extremities.

\section{Exclusion Criteria}

Patients presenting with

- Wet gangrene due to venous obstruction.

- Low platelet count $(<1,50.000)$

- Bleeding disorder.

\section{Procedure}

All patients admitted with peripheral arterial ulcers were evaluated for participation in the study on the basis of inclusion and exclusion criteria given above. Written informed consent was taken from the patient prior to the enrolment.

\section{Initial Evaluation}

Detailed demographic profile was recorded and history of present illness, intermittent claudication, duration of pregangrenous or gangrenous changes, duration of ulcer, precipitating events for arterial ulcers like, traumatic or spontaneous appearance of lesions (blackening of skin or ulceration), history of infection, smoking, hypertension, diabetes mellitus, intermittent claudication and other relevant details were recorded. All the baseline investigations including complete blood count, kidney function test, liver function tests, blood sugar level, color doppler of the affected limb were done.

\section{Clinical Examination}

Blood pressure was measured in both arms. Systemic clinical examination, clinical signs of arterial ulcers: pulselessness, pain, pallor, polar, punched-out defect, and pressure sites (6P's), condition of skin in affected limb, trophic changes, description of ulcer (length, width, surface area, site, granulation tissue, resolution of inflammation) was done. Palpation of all peripheral pulses on the affected side (radial, ulnar, brachial, axillary, dorsalis pedis, anterior tibial, posterior tibial, popliteal and femoral arterial pulsation) whether present, absent or decreased.

The diagnosis of peripheral arterial disease is based of clinical examination and confirmed by Color Doppler. After the diagnosis, the patients were subjected to required 
interventional procedure for thrombosis and occlusive arterial disease and then surgical treatment, for example: limbs with pre gangrenous changes were debrided and gangrenous limbs were amputated. Broad spectrum antibiotics were given in presence of infected wounds. The systemic antibiotics and other medications were allowed throughout the study protocol if indicated. In case of low haemoglobin blood was transfused to build up haemoglobin above $10 \mathrm{gm} \%$. After adequate control of infection, the wounds were treated according to the treatment protocols of the group, to which the patient was allotted.

\section{Intervention}

Treatment group were treated with PRP infiltration using the STARS PRP protocol: 8 Ten mL whole blood was obtained by venipuncture in acid citrate dextrose (ACD) tubes. The blood was not chilled at any time before or during platelet separations and was centrifuged at $1200 \mathrm{rpm}$ for 10 minutes. RBCs settle in the lower portion of test tube whereas plasma remains in upper part. Plasma was extracted and collected in separate ACD test tube and further re-centrifuged at $2000 \mathrm{rpm}$ for 10 minutes. The plasma further separates into upper buffy coat, platelet poor plasma (PPP) and the lower 2-4 mL layer containing platelet rich plasma (PRP). The process is performed at a room temperature of $22-24{ }^{\circ} \mathrm{C}$. This autologous PRP was then locally infiltrated in the wound margins through a $22 \mathrm{G}$ needle, just like a local infiltration of local anesthesia, at a distance of approximately $0.2 \mathrm{~mL} / \mathrm{cm}$ with equal quantity. The process was repeated every 4 th day (gap of 3 days). Local dressing was performed on alternate days, with normal saline only. Such PRP infiltrations were done till the wound surface area reduced to half.

In the control group ulcers were treated with local dressing material as per conventional treatment protocols i.e. with hydrogen peroxide and betadine, done daily till the wound surface area reduced to half.

Patients were assessed at day 0 and followed up at day 4 , $8,15,20,30$ and 60 days and length and width of wound were measured.

\section{Outcome}

Outcomes were assessed at baseline and at day 4, 8, 12, 15, 30 and 60 . Day 60 was the end point of the study and for wounds healed before day 60 , the day of last follow up was considered as the end point.

\section{Primary Outcome}

1. Time of healing - Time required to for $50 \%$ reduction of the surface area of wound measured as maximum length $\mathrm{x}$ maximum width.

2. Rate of epithelization - Time required to cover $50 \%$ of total floor surface area by healthy granulation tissues.

\section{Secondary Outcome}

Length of Hospital Stay: Time from enrollment in the study till discharge.

\section{Sample Size}

$$
\mathrm{S}=\frac{r+1}{r} \quad \frac{\mathrm{Pq}\left(\mathrm{z}_{\alpha / 2}+\mathrm{z}_{\beta}\right)^{2}}{(\mathrm{P} 1-\mathrm{P} 2)^{2}}
$$

Where,

$r=$ Ratio of control to case

$\mathrm{P}=$ average proportion exposed $=$ proportion of cases exposed

+ proportion of controls exposed $/ 2$

$\mathrm{q}=100-\mathrm{P}$

$\mathrm{Z} \dot{\alpha} / 2=0.84$

$\mathrm{Z} \beta=$ Standard normal deviate for power $80 \%-0.84$

For power $90 \%-1.28$

$\mathrm{P} 1-\mathrm{P} 2$ = proportion in cases - proportion in controls (effect size). Thus, we took $r$ as 1 , as we include equal number of cases and control. As per Kontopodis et al. ${ }^{8}$ ulcer area reduction $>50 \%$ was seen in $86 \%$ patients in treatment group and $73 \%$ in the control group, while ulcer area reduction of $>90 \%$ was seen in $83 \%$ patients of treatment group vs $56 \%$ patients among the control group. We expected an overall difference of $20 \%$ in the rate of healing of ulcer among the treatment and control group. So, we took $\mathrm{P} 1=83 \%$ and $\mathrm{P} 2=$ $63 \%$ and $\mathrm{P} 1-\mathrm{P} 2=20$

So,

$\mathrm{p}=\mathrm{P} 1+\mathrm{P} 2 / 2=63+83 / 2=73$

$q=100-P=27$

Took the power of the study as $90 \%$, inserted the values in the formula,

$\mathrm{S}=\frac{2 * 73 * 27 *(0.84+1.28)^{2}}{(83-63)^{2}}=44.2$

Thus, 40 participants were included in each group and the sample size was 80 .

\section{Randomization}

The patients were randomized into two groups by simple randomization, using computer generated programme in 1:1 ratio, a random allocation sequence was generated and sequential patient consenting to participate in the study were allocated in the respective group as per the allocation sequence.

\section{Statistical Methods}

Analysis was conducted using intention to treat principles. All participants were included with available data at both, the baseline and subsequent follow up visits. The data was entered into the Excel spread sheet. Chi-square test was used to do descriptive and inferential statistics for the purpose of statistical analysis. Software used for the purpose was SPSS 24.0 version and Graph Pad Prism 7.0 version. For considering level of significance, $p$ value was $p<0.05$. ANOVA was applied to detect statistically the significant difference in all the followups between the two groups. 


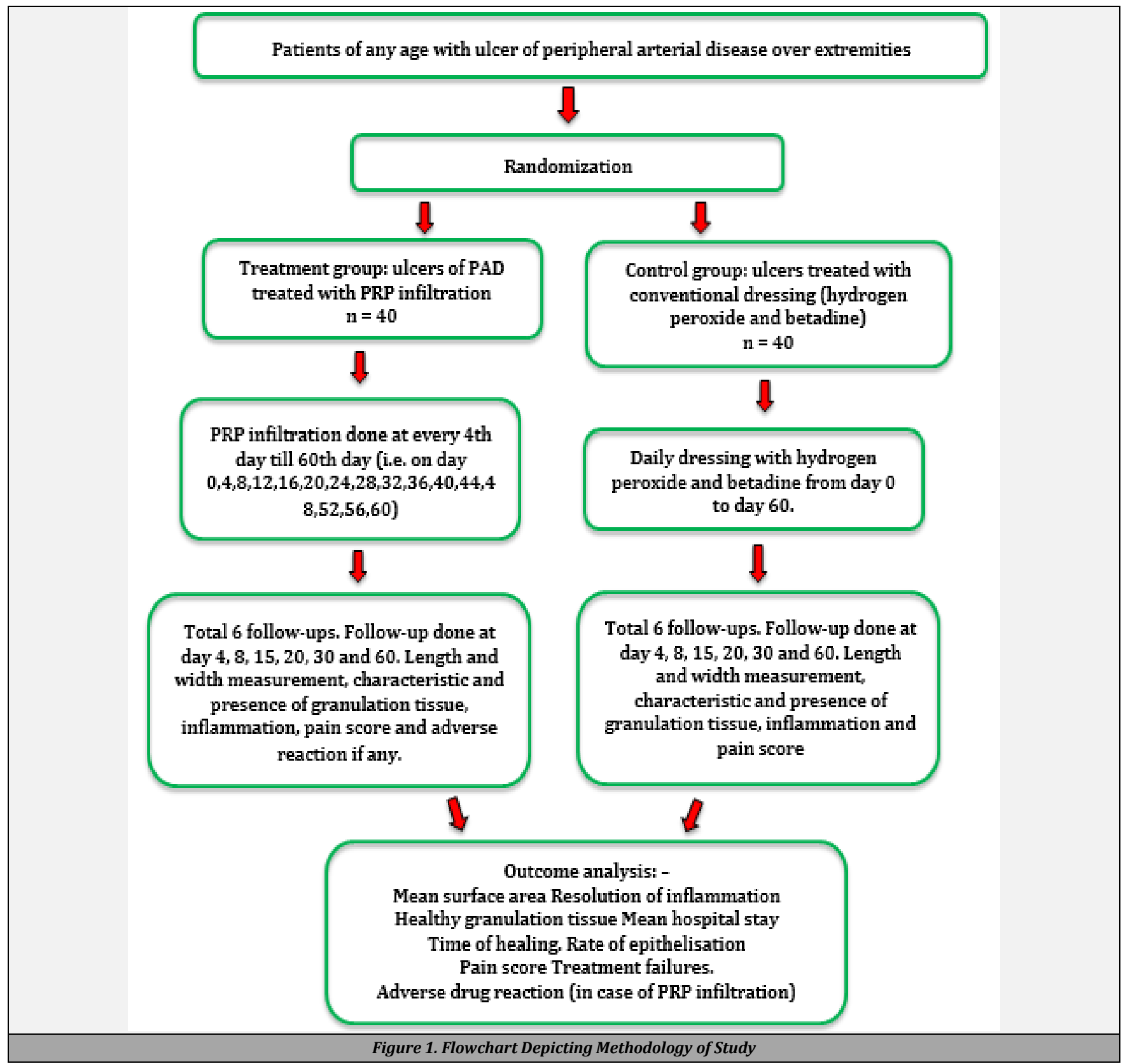

\begin{tabular}{|c|c|c|c|c|}
\hline \multicolumn{5}{|c|}{ RESULTS } \\
\hline Age & Control & Treatment & Total & Percentage \\
\hline $25-36$ & 2 & 0 & 2 & 2.5 \\
\hline $37-48$ & 7 & 11 & 18 & 22.5 \\
\hline $49-60$ & 18 & 18 & 36 & 45 \\
\hline $60-71$ & 10 & 7 & 17 & 21.25 \\
\hline $72-83$ & 3 & 4 & 7 & 8.75 \\
\hline Total & 40 & 40 & 80 & 100 \\
\hline
\end{tabular}

Table 1. Age range of patients was between 25 - 83 years. The mean age of study participants was 56.13 years with a standard deviation of 11.38 years. 36 participants belonged to age group of 49-60 years (45\%). Least number of participants belonged to the age group $25-36$ years $(2.5 \%)$ and $72-83$ years $(8.75 \%)$. There were 72 males $(90 \%)$ and 8 females $(10 \%)$ in this study. Male to female ratio was 9:1. Among control group 37 (92.5\%) study participants were male while $3(7.5 \%)$ were female and in the treatment group $35(87.5 \%)$ study participants were male while $5(12.5 \%)$ were female.

\begin{tabular}{|c|c|c|c|c|c|c|c|}
\hline $\begin{array}{l}\text { Past } \\
\text { History }\end{array}$ & Control & Treatment & Total & I Value & & $\begin{array}{c}\text { Asymptotic } \\
\text { f Significance } \\
\text { (2-Sided)* }\end{array}$ & 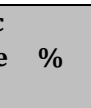 \\
\hline Smoking & 20 & 21 & 41 & 0.05 & 1 & 0.823 & $51.25 \%$ \\
\hline $\begin{array}{l}\text { Diabetes } \\
\text { Mellitus }\end{array}$ & 19 & 19 & 38 & 0 & 1 & 1 & $47.5 \%$ \\
\hline Hypertension & 25 & 26 & 51 & 0.054 & 1 & 0.816 & $63.75 \%$ \\
\hline
\end{tabular}

Table 2. Out of 80 patients, $41(51.25 \%)$ had history of smoking, $38(47.5 \%)$ of diabetes and 51 (63.75\%) of hypertension. Past history of smoking, diabetes and hypertension was not significantly different in treatment and control groups. 


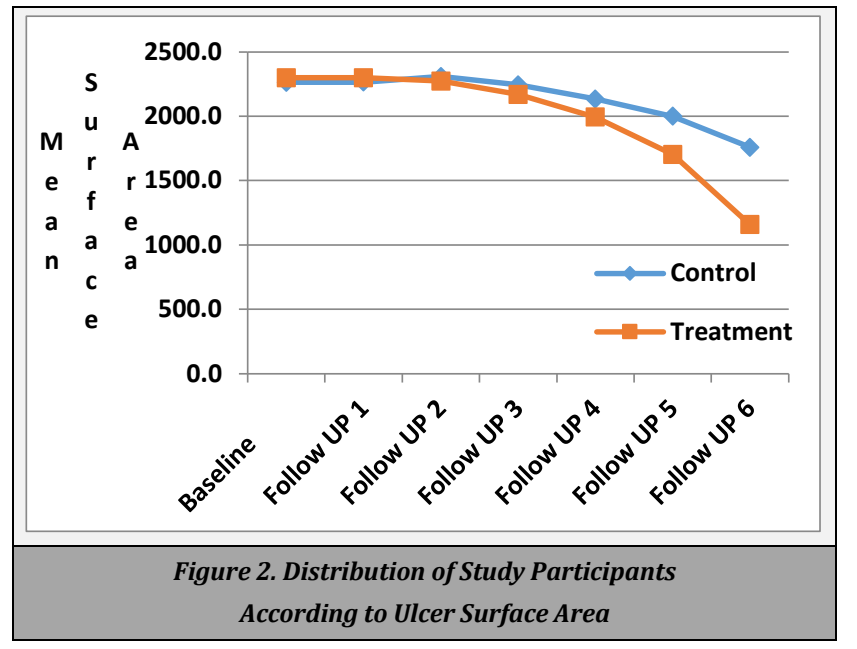

Figure 2. Outcomes were assessed on day $0,4,8,15,30$ and 60 days which were represented as baseline, follow up 1, 2, 3, 4, 5 and 6 respectively. The mean surface area of ulcer reduced from baseline measurement of $2262.5 \mathrm{~mm}^{2}$ to $2243.6 \mathrm{~mm}^{2}$ at 15 days, $1998.9 \mathrm{~mm}^{2}$ at 1 month and $1758.4 \mathrm{~mm}^{2}$ at the end of two months period in control group and in treatment group, the mean surface area of ulcer decreased from $2298.9 \mathrm{~mm}^{2}$ to $2169 \mathrm{~mm}^{2}$ at 15 days, $1703.6 \mathrm{~mm}^{2}$ at the end of 1 month and $1158.1 \mathrm{~mm}^{2}$ at the end of two months period. The mean surface area of ulcer in the control group decreased from $\left(2262.47 \mathrm{~mm}^{2} \pm 1739.2 \mathrm{~mm}^{2}\right)$ to $\left(1758.4 \mathrm{~mm}^{2} \pm 1556.18 \mathrm{~mm}^{2}\right)$ and it decreased from $\left(2298.8 \mathrm{~mm}^{2} \pm 1906.45 \mathrm{~mm}^{2}\right)$ to $\left(1158.1 \mathrm{~mm}^{2} \pm 1402.4 \mathrm{~mm}^{2}\right)$ in treatment group at the end of 60 days. There was a statistically significant difference in the surface area of ulcer by the end of $6^{\text {th }}$ follow up $(p=0)$.

No change observed in mean surface area at $1^{\text {st }}$ follow-up in either group. At $2^{\text {nd }}$ follow-up, mean reduction of $0.18 \%$ and $1.36 \%$ in the surface area in control group and treatment group was observed respectively $(\mathrm{p}=0.005)$. At $3^{\text {rd }}$ follow-up, mean reduction of $2.35 \%$ and $7.55 \%$ in the surface area of control and treatment group was observed $(\mathrm{p}=0)$. At $4^{\text {th }}$ follow-up, mean reduction of $8.22 \%$ and $18.57 \%$ in the surface area, of control and treatment group was observed $(\mathrm{p}=0)$. At the $5^{\text {th }}$ follow-up mean reduction was $16.19 \%$ and $35.16 \%$ in the surface area of the control group and treatment group respectively $(\mathrm{p}=0)$. In the control group there was a mean reduction in surface area of $29.89 \%$ and in the treatment group of $66.22 \%$ at the end of 60 days period $(p=0)$. On applying ANOVA, there was statistically significant difference in the percentage reduction in ulcer surface area in all the follow-ups between the two groups.

In the treatment group, surface area of 5 wounds (12.5\%) reduced to half of its original surface area at $5^{\text {th }}$ follow-up i.e. 30 days. No change was observed in the control group at $5^{\text {th }}$ follow-up. In the treatment group, surface area of 27 wounds $(67.5 \%)$ reduced to half of its original surface area and in control group 2 wounds (5\%) reduced to half of its original surface area at $6^{\text {th }}$ follow-up i.e. 60 days. Thus, time required $50 \%$ reduction in the surface area of the wound was 4 weeks for 5 wounds and 8 weeks for 27 wounds in treatment group and 8 weeks for 2 wounds in control group.

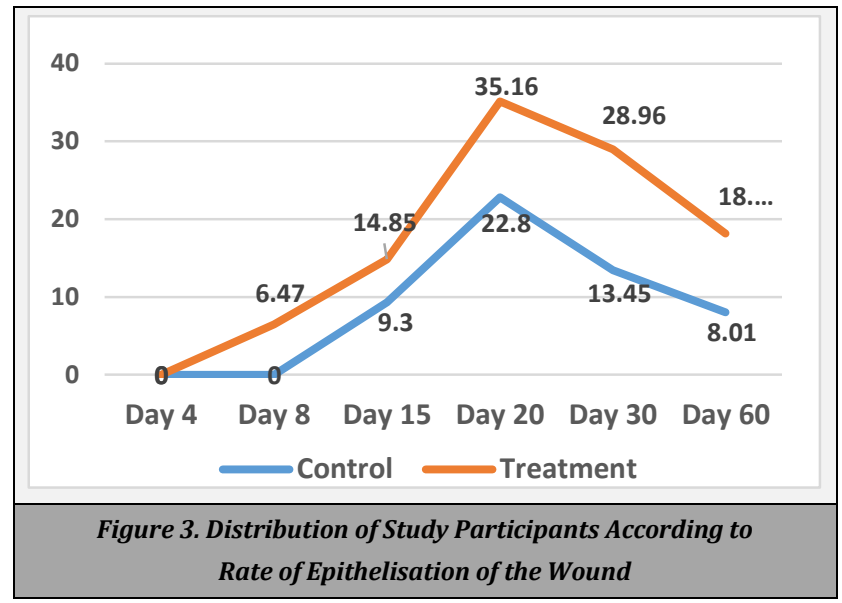

Figure 3. The difference between rate of epithelization was statistically significant between treatment and control groups at day $15(\mathrm{p}=0.053), 20(\mathrm{p}=0.031), 30(\mathrm{p}=0.012)$ and day 60 $(\mathrm{p}=0)$. The mean rate of epithelisation was $8.92 \mathrm{~mm}^{2} /$ day and $17.27 \mathrm{~mm}^{2}$ /day in control group and treatment group respectively.

No significant adverse drug reaction was observed in treatment group following PRP infiltration.

\section{DISCUSSION}

\section{Age and Gender Distribution of Participants}

In our study, the age of the study participants ranged between 25 - 83 years. The mean age being $56.13 \pm 11.38$ years, majority of them (45\%) belonged to the age group of 44 -67 years in both treatment and control groups.

Ridker et al. ${ }^{9}$ found the mean age group of the study participants to be $62.9 \pm 9.5$ years. Kontopodis et al. ${ }^{10}$ found that the mean age of study participants was 65 years. Vainas et al. ${ }^{11}$ observed the mean age of the study participants was 65 years. Anitua et al. ${ }^{12}$ reported age distribution of the participants was $51 \pm 17$ years. Thus, the age group considered for the study was in congruence with published literature. We observed more males than females in our study, ratio being 9:1. Ahmed et al. ${ }^{13}$ observed more males (67\%) than females (33\%). Kontopodis et al. ${ }^{10}$ also reported in their study that the male to female ratio was 4:1.

\section{Past History (Risk Factors and Co-Morbidities)}

Analysing the past history helps to understand the co morbidities, and other factors that may affect healing. This in turn will help in identifying the confounders and their distribution if there are any.

Half of the participants $(51.25 \%)$ in our study were smokers. Smoking is suggested to affect PAD and the wound healing. Khalifa et al reported smoking in 34\% of the participants and peripheral vascular disease was significantly associated with smoking. ${ }^{14}$ Setta et al reported 33\% smoking rate. 15

The smoking rate in our study is higher than the published literature which may be due to different rate of tobacco smoking in various regions also the current study was conducted in a rural area. 
In a report by the American Heart Association, it is stated that diabetes and smoking are the strongest risk factors for PAD. Other well-known risk factors are advanced age, hypertension and hyperlipidaemia. ${ }^{16}$

Both diabetes and hypertension are known to be predisposing factors for ulceration due to neuropathy and atherosclerosis. Diabetes affects the immunity as well and plays a role in healing. Patients with history of diabetes are known to have an increased incidence of non-healing ulcers compared to general population. $47.5 \%$ of study participants were diabetic. There was no statistically significant difference in the history of diabetes between the treatment and control group. We observed that $63.75 \%$ of the participants were hypertensive. 25 in control and 26 in treatment group. But we did not observe any statistically significant difference in the history of hypertension between the treatment and control group. The $\mathrm{p}$ - value found by using the chi square test for the same was $<0.05$.

Setta et al found $70 \%$ of the participants were hypertensives. ${ }^{15}$ Similarly Atosona et al reported $60 \%$ of the participants were hypertensive. ${ }^{17}$ Criqui MH reported $20.9 \%$ patients were diabetic and he reported a significant association of diabetes with cardio vascular disease. ${ }^{18}$

\section{Surface Area of Ulcer and Percentage Reduction}

The mean surface area of ulcer in control group decreased from $\left(2262.47 \mathrm{~mm}^{2} \pm 1739.2 \mathrm{~mm}^{2}\right)$ to $\left(1758.4 \mathrm{~mm}^{2} \pm 1556.18\right.$ $\left.\mathrm{mm}^{2}\right)$ and $\left(2298.8 \mathrm{~mm}^{2} \pm 1906.45 \mathrm{~mm}^{2}\right)$ to $\left(1158.1 \mathrm{~mm}^{2} \pm\right.$ $1402.4 \mathrm{~mm}^{2}$ ) in the treatment group at the end of 60 days. Four ulcers had completely healed at sixth follow up in treatment group.

Kakudo et al ${ }^{19}$ assessed the effectiveness of PRP in which initial wound size ranged between $2.1 \mathrm{~cm}^{2}$ to $12.5 \mathrm{~cm}^{2}$. More than half the wounds had healed by 4 weeks and remaining had decreased in size. Time taken for complete healing of ulcer was between 3 to 14 weeks. Kontopodis et al. ${ }^{10}$ compared the baseline mean \pm standard deviation of ulcer area between treatment group $\left(4.2 \mathrm{~cm}^{2} \pm 3.9 \mathrm{~cm}^{2}\right)$ and control group (3.8 $\left.\mathrm{cm}^{2} \pm 3.5 \mathrm{~cm}^{2}\right)$ indicated nonsignificant differences $(\mathrm{p}=0.82)$. With regard to clinical improvement (ulcer area reduction $>50 \%$ ), there were $36 / 42(86 \%)$ improved ulcers in treatment group and $22 / 30(73 \%)$ in control group, and this difference was not statistically significant $(\mathrm{P}=0.23)$. Rate of ulcer area reduction $>90 \%$ and it was significantly higher in treatment group (35/42\% to $83 \%$ vs $17 / 30 \%$ to $56 \%, \mathrm{P}=0.02$ ).

There was significant difference in reduction of surface area of ulcer in treatment group as compared to controls in $6^{\text {th }}$ follow up (60 days).

In control group there was a mean reduction of $29.89 \%$ and $66.22 \%$ in the treatment group in the surface area at the end of 60 days period. Leon et al. ${ }^{20}$ found that in $86.3 \%$ of wounds, $47.5 \%$ area reduction occurred, and $90.5 \%$ of wounds had a $63.6 \%$ volume reduction. Anitua et al. ${ }^{12}$ measured the mean percentage of ulcer surface area healed in their study population, which was $72.94 \%$ in patients treated with GFs versus $21.48 \%$ in those receiving standard care, a difference that was statistically significant. The present study demonstrates similar results with more rapid decrease in the ulcer surface area of PRP treated group as compared to conventional treatment.

\section{Time of Healing}

Time of healing in this study is taken as, the time required to reduce the surface area of the wound to half of its original surface area, which was 4 weeks for $5(12.5 \%)$ wounds and 8 weeks for 27 (67.5\%) wounds in treatment group.

Suthar et al. ${ }^{21}$ found that all the patients showed signs of wound healing with reduction in wound size, and the mean time duration to ulcer healing was 8.2 weeks.

Kontopodis et al. ${ }^{10}$ observed that ulcer area reduction $>50 \%$ was observed in 58/72 (80.5\%) patients while reduction $>90 \%$ was achieved in $52 / 72(72.22 \%)$ patients.

Driver VR et al. ${ }^{5}$ found a healing rate of $81.3 \%$ in patients treated with PRP in the same time that significantly fewer patients in the control group (42.1\%) presented complete wound healing.

\section{Rate of Epithelialisation}

The mean rate of epithelisation was $8.92 \mathrm{~mm}^{2} /$ day $(0.0892$ $\mathrm{cm}^{2} /$ day) in control group and it was $17.27 \mathrm{~mm}^{2} /$ day $(0.1727$ $\mathrm{cm}^{2} /$ day) in treatment group. There is significant difference between the rate of epithelisation in the treatment and control group at $3^{\text {rd }}, 4^{\text {th }}, 5^{\text {th }}$ and $6^{\text {th }}$ follow-up.

Vickie R. Driver et al. ${ }^{5}$ observed that the average wound area closure rate per day was $0.051 \mathrm{~cm}^{2}$ for the PRP gel group and it was $0.054 \mathrm{~cm}^{2}$ for the control group in the PP database of their study. In the majority database the wound area closure per day $0.042 \mathrm{~cm}^{2}$ for PRP gel group and $0.043 \mathrm{~cm}^{2}$ for the control group.

There are not many studies done on rate of epithelization. This variation may be due to different method of preparation of PRP and also due to different mode of administering PRP.

The mean duration of stay in control group was 17.6 days and it was 14.2 in treatment group. The difference found was not statistically significant.

Saad et al. ${ }^{15}$ found that the healing in PRP group was significantly faster $(P<0.005)$. PRP enhances healing of chronic diabetic foot ulcers leading to lesser hospital stay compared to the other group.

Leon et al. ${ }^{20}$ observed positive response in $96.5 \%$ of wounds within 2.2 weeks with 2.8 treatments. In $86.3 \%$ of wounds, $47.5 \%$ area reduction occurred, and $90.5 \%$ of wounds had a $63.6 \%$ volume reduction, resulting in lesser hospital stay compared to controls.

It can be observed that the healing of ulcer including surface area, resolution of inflammation and appearance of healthy granulation tissue is faster in treatment group compared to the controls. Most participants in this study belonging to treatment group stayed in hospital for longer duration due to transportation issues.

\section{CONCLUSIONS}

PRP is an effective method for healing of wounds resulting from peripheral arterial disease. It is evident from this study that, wounds infiltrated with PRP, using STAR's protocol, 8 healed faster. The rate of wound healing was rapid in treatment group as seen from the significant decrease in surface area of wound and faster rate of epithelization. No adverse drug reactions were reported. Duration of hospital 
stay was shorter. Hence treatment with PRP is more effective as compared to conventional dressing in treatment of peripheral arterial ulcers.

\section{Limitations}

Long term effects of PRP on wound healing could not be assessed due to short duration of study i.e. 2 years and maximum follow-up of 2 months.

\section{Recommendations}

PRP can be more extensively used in the treatment of wounds resulting from peripheral arterial disease due to its regenerative properties.

Further studies to quantify the PRP cycles for various sites and sizes of ulcers and to quantify the efficacy of PRP in different etiologies need to be considered and larger randomized controlled trials with longer duration of follow-up need to be conducted to monitor the long-term efficacy of PRP.

Authors thank Dr. Chandanwale, Mrs. Chandanwale, Mr. Kothule, Mrs. Kothule and Ms. Anna Mary Jose for all the support and encouragement. taken.

Approval from institutional ethical committee, DMIMS (DU) was

Informed written consent was obtained from all the patients.

Datasets of this study collected during and/or analysed during the current study are available from the corresponding author on reasonable request.

Financial or Other Competing Interests: None.

\section{REFERENCES}

[1] Das S. A manual on clinical surgery. $9^{\text {th }}$ edn. Kolkata: Dr. S. Das 2011: p. 61.

[2] Primc D, Ivančić A, Saftić I, et al. Treatment of advanced peripheral arterial insuffificiency in the elderly. Coll Antropol 2015;39(1):67-70.

[3] Williams N, O'Connell PR, McCaskie AW, eds. Bailey \& Love's short practice of surgery. $7^{\text {th }}$ edn. Boca Raton, FL: CRC Press 2018.

[4] Richard JL, Parer-Richard C, Daures JP, et al. Effect of topical basic fibroblast growth factor on the healing of chronic diabetic neuropathic ulcer of the foot. A pilot, randomized, double-blind, placebo-controlled study. Diabetes Care 1995;18(1):64-9.

[5] Driver VR, Hanft J, Fyling CP, et al. A prospective, randomized, controlled trial of autologous platelet-rich plasma gel for the treatment of diabetic foot ulcers. Ostomy Wound Manage 2006;52(6):68-87.

[6] Bennett SP, Griffiths GD, Schor AM, et al. Growth factors in the treatment of diabetic foot ulcers. $\mathrm{Br} \mathrm{J}$ Surg 2003;90(2):133-46.
[7] Wrotniak M, Bielecki T, Gaździk TS. Current opinion about using the platelet-rich gel in orthopaedics and trauma surgery. Ortop Traumatol Rehabil 2007;9(3):227-38.

[8] Shrivastava S, Singh PK, Taywade S. STARS therapy: Sandeep's technique for assisted regeneration of skin. J Orthopaedics and Allied Sci 2016;4(1):5.

[9] Ridker PM, Cushman M, Stampfer MJ, et al. Plasma concentration of $\mathrm{C}$-reactive protein and risk of developing peripheral vascular disease. Circulation 1998;97(5):4258.

[10] Kontopodis N, Tavlas E, Papadopoulos G, et al. Effectiveness of platelet-rich plasma to enhance healing of diabetic foot ulcers in patients with concomitant peripheral arterial disease and critical limb ischemia. Int J Low Extrem Wounds 2016;15(1):45-51.

[11] Vainas T, Stassen FR, de Graaf R, et al. C-reactive protein in peripheral arterial disease: relation to severity of the disease and to future cardiovascular events. J Vasc Surg 2005;42(2):243-51.

[12] Anitua E, Aguirre JJ, Algorta J, et al. Effectiveness of autologous preparation rich in growth factors for the treatment of chronic cutaneous ulcers. J Biomed Mater Res B Appl Biomater 2008;84(2):415-21.

[13] Ahmed M, Reffat SA, Hassan A, et al. Platelet-rich plasma for the treatment of clean diabetic foot ulcers. Ann Vasc Surg 2017;38:206-11.

[14] Khalifa WA. Risk factors for diabetic foot ulcer recurrence: a prospective 2-year follow-up study in Egypt. Foot (Edinb) 2018;35:11-5.

[15] Setta HS, Elshahat A, Elsherbiny K, et al. Platelet-rich plasma versus platelet-poor plasma in the management of chronic diabetic foot ulcers: a comparative study. Int Wound J 2011;8(3):307-12.

[16] American Diabetes Association. Peripheral arterial disease in people with diabetes. Diabetes Care 2003;26(12):3333-41.

[17] Atosona A, Larbie C. Prevalence and determinants of diabetic foot ulcers and lower extremity amputations in three selected tertiary hospitals in ghana. J Diabetes Res 2019;2019:1-9.

[18] Criqui MH. Peripheral arterial disease--epidemiological aspects. Vasc Med 2001;6(3 Suppl):3-7.

[19] Kakudo N, Kushida S, Ogura T, et al. The use of autologous platelet-rich plasma in the treatment of intractable skin ulcer: a case series. J Regenerative Med 2012;1(3):29-32.

[20] de Leon JM, Driver VR, Fylling CP, et al. The clinical relevance of treating chronic wounds with an enhanced near-physiological concentration of platelet-rich plasma gel. Adv Skin Wound Care 2011;24(8):357-68.

[21] Suthar M, Gupta S, Bukhari S, et al. Treatment of chronic non-healing ulcers using autologous platelet rich plasma: a case series. J Biomed Sci 2017;24(1):16. 